J. KOLLAR

\title{
CLUSTER PERTURBATION THEORY
} FOR CLASSICAL FLUIDS I.

Hungarian Academy of Sciences

CENTRAL

RESEARCH

INSTITUTE FOR

PHYSICS

BUDAPEST 
CLUSTER PERTURBATION THEORY FOR CLASSICAL FLUIDS I.

by

J. Kollár

Central Research Institute for physics

H-1525 Budapest 114, P.O.B. 49, Hungary

HU ISSN $0368 \quad 5330$

ISBN $963 \quad 371758 \quad 2$ 


\section{ABSTRACT}

A perturbational method in the form of a power series in a "softness parameter" $\xi$ has been developed for determining the thermodynamic properties and the pair correlation function of a real fluid using the thermodynamic quantities and distribution functions of a reference system. The method makes possible a simple treatment for the higher order terms and enables us to take into account some parts of the higher order terms in the usual density-dependent form of the thermodynamic quantities, in terms of lower order terms, namely those parts, that can be expressed in terms of the dervatives of lower order distribution functions with respect to the density. Thus we expect to achieve higher accuracy compared to the usual treatments in the case, when we know, for example, only the pair correlation function of the reference system, since the method makes full use of the information content of the pair function. Besides, new conditions have been proposed for the optimal choice of the reference system.

АННОТАЦИЯ

Пертурбационный метод в форме степенного ряда по "параметру мягкости" $\xi$ развит для определения термодинамических свойств и парной корреляционной Функции реальной жидкости. При этом используются известные термодинамические функции и функции распределения системы, выбранной в качестве референции. Метод дает возможность достоточно просто получать в разложении члены высших порядков. Одновременно он позволяет учесть часть членов высших порядков для термодинамических величин в обычной зависяцей от плотностй форме /часть, которая может быть выражена через производные по плотности низших порядков/. Таким образом представляется, что возможно проводить вычисления с высокой точностью в случае, когда известна только парная корреляционная функция системы рефернции. Кроме того, предложены новые условия для оптимального выбора системы референции.

\section{KIVONAT}

Perturbációs módszert fejlesztettünk ki egy छ "lágysági paraméter" hatványai szerint haladó sor alakjában egy reális folyadék termodinamikai tulajdonságainak és párkorrelációs függvényének a meghatározására egy referencia-rendszer termodinamikai mennyiségeinek és eloszlásfüggvényeinek a felhasználásával. A módszer lehetôvé teszi a magasabbrendủ tagok egyszerü kezelését és a termodinamikai mennyiségek szokásos sürüség-függó alakjában fellépô magasabbrendü tagok egy részének figyelembe vételét alacsonyabbrendü tagok segitségével /igy azokat a részeket tudjuk figyelembe venni, amelyek alacsonyabbrendü eloszlásfüggvények sürüség szerinti deriváltjaival kifejezhetôk/. Igy a szokásos módszerekkel összehasonlitva nagyobb pontosság érhetõ el abban az esetben, amikor csak a referencia-rendszer párkorrelációs függvényét ismerjük, mivel a módszer a párkorrelációs függvény teljes információtartalmát felhasználja. Emellett uj feltételeket javasoltunk a referencia-rendszer optimális meghatározására. 


\section{INTRODUCTION}

In the calculation of the thermodynamic and structural properties of real fluids the perturbational expansions - being the only viable methods besides the Monte Carlo and molecular dynamics computer simulations - are of great importance. In this kind of calculations the thermodynamic and structural properties of a fluid are expressed in terms of the properties of a "reference system", which are assumed to be known. Among these the most successful and most commonly used methods are the high temperature expansion ${ }^{1}$ (or $\lambda$-expansion), the generalized cluster expansion ${ }^{2}$ (often referred to as $\boldsymbol{\gamma}$-expansion), the optimized cluster expansion ${ }^{3}$ and their modifications ${ }^{4}$. The high temperature expansion results in a power series in a formal parameter $\lambda$ measuring the "amplitude" of the potential difference $\lambda \tilde{v}(r)=u(r)-u_{0}(r)$, and not in a kind of "softness parameter" $\xi$ measuring the "amplitude" of the difference in the Boltzmann factors

$$
\xi \Delta e(r)=e(r)-e_{0}(r)=e^{-\beta u(r)}-e^{-\beta u_{0}(r)}
$$

Therefore the $\lambda$-expansion is appropriate mainly for treating slowly varying perturbations (e.g. an attractive tail added to a hard core repulsion). This holds for the other methods as well, since - although they are not systematic expansions in $\lambda$ - their leading terms are proportional to the potential difference. An other group of perturbational theories (for simplicity, hereafter we refer to them as $\boldsymbol{\xi}$-expansions) has 
been developed for treating rapidly varying perturbations (in a narrow range of $r$ ). to describe the thermodynamic properties of the so called soft sphere systems $5,6,7$. These methods result in perturbational series actually in powers of a softness parameter $\xi$ (or in other words, a functional Taylor expansion in the difference of the Boltzmann factors $\Delta e(r)$ ), as it can be seen clearly from the free energy expression given by Andersen et al. ${ }^{7}$. The $\xi$-expansions are expected to assure a rapid convergency for the perturbational series in the cases, when the perturbation (which may vary rapidly) is localized in a narrow range of $r$ in the small $r$-region (usually around some core radius). The main reason for this is the following. Since in this case the perturbation appears in the region which is of primary importance from the point of view of determining the pair function, in the $\boldsymbol{E}$-expansion already the zeroth order term gives a reasonable result for the pair distribution function $n_{2}(r)$ in the form $\frac{e(r)}{e_{0}(r)} r_{2}^{0}(r)$ $\left(n_{2}^{0}\right.$ is the pair distribution function of the reference system), in contrast to the zeroth order term of the high temperature expansion, where $n_{2}(r)=n_{2}^{0}(r)$ (as we can see from the first order term of the free energy). The latter is appropriate, therefore, for treating slowly varying perturbations appearing in a region which has little effect on the pair correlation function.

In these methods the derivation of the higher order terms is usually rather cumbersome, if there exists any viable prescription for their calculation at all. In this paper we present 
a simple method in terms of which one can relate the thermodynamic and structural properties of a real fluid to those of a reference system in a compact, physically transparent form. The method of derivation is similar to that of the usual cluster expansion of the virial series. The series expansion developed in this way in its original form (being a kind of a $\xi$-expansion) is mainly appropriate for the description of rapidly varying perturbation, but expanding the difference of the Boltzmann factors in terms of the potential difference $v(r)$, we can recover the formulas of the high temperature expansion as well.

The method in its present form contains an approximation (decoupling of certain cluster integrals) which is, however, not a necessary condition for carrying out the calculation. In the exact result some corrections contribute to the higher. order terms presented here, but the calculation of these corrections is easier by using an other technique (the diagrammatic expansion) and it will be published elsewhere ${ }^{8}$. The reason for applying this decoupling approximation is threefold. First, it allows us to derive the thermodynamic quantities in a simple physically transparent form. Second, this formulation of the problem makes it possible to take into account some parts of the terms containing higher order correlation functions in the usual density-dependent form of the thermodynamic quantities, in terms of lower order terms, permitting to achieve higher accuracy in the important special case, when we know only the pair correlation function of the reference system. Finally these corrections are usually small, and in applications they 
are of little importance, because the higher order correlation functions of the reference system are, in any case, unknown (the calculation of the lowest order correction needs the knowledge of the four-particle correlation function of the reference system). The application of this method for a hard sphere reference system is given in the following paper.

\section{Description of the method}

Consider a homogeneous system of volume $\mathrm{V}$ with $\mathrm{N}$ identical classical particles, where the interaction energy is the sum of pair interactions:

$$
E_{N}\left(\underline{r}^{N}\right)=\sum_{i<j} u\left(r_{i j}\right)
$$

Here the symbolic notation $\left\{r^{N}\right\}$ stands for the coordinates $\underline{r}_{1}, \underline{r}_{2} \cdots \underline{r}_{N}$, and $\underline{r}_{i j}=\underline{r}_{i}-\underline{r}_{j}$. The canonical partition function of the system has the form

$$
Q_{N}\left(V_{1} T\right)=\frac{1}{N ! \lambda^{3 N}} \int e^{-\beta E_{N}\left(\underline{r}^{N}\right)} d \underline{r}^{N}
$$

where $\lambda=h /(2 \pi m k T)^{1 / 2}$ and $\beta=1 / k T$ (k stands for the Boltzmann constant, $\mathrm{T}$ is the temperature). We can now rewrite the exponential by introducing formally the interaction energy $E_{N}^{0}=\sum_{i<j} u_{0}\left(\underline{r}_{i j}\right)$ of a reference system (hereafter the index "o" always refers to the reference system): 


$$
e^{-\beta E_{N}\left(\underline{r}^{N}\right)}=e^{-\beta E_{N}^{0}\left(\underline{r}^{N}\right)} W_{N}\left(\underline{r}^{N}\right)
$$

Here we introduced the notation

$$
W_{N}\left(\underline{r}^{N}\right)=e^{-\beta \sum_{i<j} v\left(\underline{r}_{i j}\right)}
$$

Let us now define the functions $U_{N}\left(\underline{r}^{N}\right)$ instead of $W_{N}\left(\underline{r}^{N}\right)$ by the equations

$$
\begin{aligned}
W_{1}\left(\underline{r}^{1}\right)= & u_{1}\left(\underline{r}_{1}\right)=1 \\
W_{2}\left(\underline{r}^{2}\right) & =1+u_{2}\left(\underline{r}_{1} \underline{r}_{2}\right) \\
W_{3}\left(\underline{r}^{3}\right)= & 1+u_{2}\left(\underline{r}_{1} \underline{r}_{2}\right)+U_{2}\left(\underline{r}_{2} \underline{r}_{3}\right)+U_{2}\left(\underline{r}_{3} \underline{r}_{1}\right) \\
& \quad+u_{3}\left(\underline{r}_{1} \underline{r}_{2} \underline{r}_{3}\right) \\
W_{N}\left(\underline{r}^{N}\right) & =\sum u_{N_{1}} u_{N_{2}} \ldots ; \quad ; \quad \sum_{k} N_{k}=N
\end{aligned}
$$

where the summation of the last equation extends, first, over all possible partitiones of $\mathrm{N}$ as a sum of positive integers and, second, for a given partitio over all possible ways in which $\mathrm{N}$ atoms can be devided into groups consisting, respectively, of $\mathrm{N}_{1}, \mathrm{~N}_{2}, \ldots$ atoms. If a partitio is such that among the $\mathrm{N}_{\mathrm{i}}-\mathrm{s}$ there are $\mathrm{N}-\mathrm{k} 1^{\prime} \mathrm{s}, \mathrm{k}_{2} 2^{\prime} \mathrm{s}, \ldots \mathrm{k}_{\ell} \ell^{\prime} \mathrm{s}, \ldots$, the number of terms corresponding to that particular partitio will be equal to 


$$
\frac{N !}{(N-k) !} \frac{1}{\prod_{e=2} k_{e} !(l !)^{k_{e}}}
$$

and

$$
\sum_{e=2} l k_{e}=k
$$

Thus, using equations. (2) and taking into account that the number of terms corresponding to a given partitio is given by (3a), $\mathrm{W}_{\mathrm{N}}$ can be reformulated as

$$
W_{N}\left(\underline{r}^{N}\right)=1+\sum_{k=2}^{N} \frac{N !}{(N-k) !} \widetilde{W}_{k}\left(r^{k}\right)
$$

where we have used the symbolic notation

$$
\widetilde{W}_{k}\left(\underline{r}^{k}\right)=\sum_{k_{2} k_{3} \ldots} \frac{1}{k_{2} !}\left[\frac{u_{2}\left(\underline{r}^{2}\right)}{2 !}\right]^{k_{2}} \frac{1}{k_{3} !}\left[\frac{u_{3}\left(r^{3}\right)}{3 !}\right]^{k_{3}} \ldots
$$

In the last equation the summation extends over all possible values $\mathrm{k}_{2}, \mathrm{k}_{3}, \ldots$ which satisfy the condition (3b). Using equation (4) the canonical partition function (1) will have the form

$$
Q_{N}(V, T)=Q_{N}^{0}(v, T)\left[1+\sum_{k=2}^{N} \int \tilde{n}_{N}^{0}\left(\underline{r}^{k}\right) \widetilde{W}_{k}\left(\underline{r}^{k}\right) d \underline{r}^{k}\right]
$$

where $\tilde{n}_{N}^{0}\left(\underline{r}^{k}\right)$ stands for the canonical k-particle distribution 
function of the reference system which is defined by

$$
\tilde{n}_{N}^{0}\left(\underline{r}^{k}\right)=\frac{1}{(N-k) !} \frac{1}{Q_{N}^{0} \lambda^{3 N}} \int e^{-\beta E_{N}^{0}\left(\underline{r}^{N}\right)} d \underline{r}^{N-k}
$$

Similarly to the derivation of the usual cluster expansion, it is more convenient now to turn to the grand canonical formalism. Using equation (5) the grand canonical partition function can be written (by rearranging the terms in the double sum) as

$$
\begin{aligned}
\Xi(\mu, v, T) & =\sum_{N=0}^{\infty} e^{\beta \mu N} Q_{N}(v, T) \\
& =\Xi_{0}(\mu, v, T)\left[1+\sum_{k=2}^{\infty} \int_{k} n_{k}\left(\underline{r}^{k}\right) \widetilde{W}_{k}\left(\underline{r}^{k}\right) d \underline{r}^{k}\right]
\end{aligned}
$$

Here $n_{k}^{0}\left(r^{k}\right)$ is the grand canonical k-particle distribution function of the reference system:

$$
n_{k}^{0}\left(\underline{r}^{k}\right)=\sum_{N=k}^{\infty} \frac{e^{\beta \mu N} Q_{N}^{0}}{\equiv_{0}} \tilde{n}_{N}^{0}\left(r^{k}\right)
$$

Now we return to the discussion of the motivation for introducing the "cluster functions" $U_{N}$ instead of $w_{N}-s$. Suppose that the potential difference $V(r)$ is zero for $r>d$. Then it is easy to show ${ }^{9}$ that $U_{N}$ is equal to zero. as soon as any one of the $\mathrm{N}$ atoms lies at a distance larger than d from all the others 
(i.e. $U_{N}=0$, if the $N$ atoms do not belong to one cluster). This property of the cluster functions will allow us to determine the volume dependence of the integrals appearing in the expression (7) for the grand canonical partition function.

From the equations (7) and (4) we can see that the grand canonical partition function consists of the sum of integrals of the type

$$
\int n_{k}^{0}\left(r^{k}\right)\left[u_{2}\left(r^{2}\right)\right]^{k_{2}}\left[u_{3}\left(r^{3}\right)\right]^{k_{3}} \cdot \cdot d \underline{r}^{k}
$$

Since a certain product $U_{2}\left(\underline{r}_{1} \underline{r}_{2}\right) \ldots U_{3}\left(\underline{r}_{3} \underline{r}_{4} \underline{r}_{5}\right) \ldots$ differs from zero only if the corresponding atoms $1,2 \ldots 3,4,5 \ldots$ form clusters, in the calculation of the integrals it seems to be reasonable to assume, that the k-particle distribution function of the reference system splits into the product of lower order distribution functions according to the given combination of the cluster functions appearing in the integrand:

$$
n_{k}^{0}\left(r^{k}\right) \approx\left[n_{2}^{0}\left(\underline{r}^{2}\right)\right]^{k_{2}}\left[n_{3}^{0}\left(\underline{r}^{3}\right)\right]^{k_{3}} \ldots
$$

This assumption exactly holds for an ideal gas reference system where $n_{k}^{0}\left(\underline{r}^{k}\right)=\rho_{0}^{k}$; here $\rho_{0}$ stands for the density of the reference system of a chemical potential $\mu$, volume $v$, and inverse temperature $\beta$ :

$$
\rho_{0}=\left(\frac{\partial P_{0}}{\partial \mu}\right)_{v_{1} \beta}
$$


The assumption (9) enables us to derive an expression for the equation of state in a close, compact form, since the integrals of the type (8). now split into the product of integrals of lower dimension:

$$
\begin{aligned}
& \int n_{k}^{0}\left(\underline{r}^{k}\right)\left[u_{2}\left(\underline{r}^{2}\right)\right]^{k_{2}}\left[u_{3}\left(\underline{r}^{3}\right)\right]^{k_{3}} \ldots d \underline{r}^{k} \\
& \approx\left[\int n_{2}^{0}\left(\underline{r}^{2}\right) u_{2}\left(\underline{r}^{2}\right) d \underline{r}^{2}\right]^{k_{2}}\left[\int n_{3}^{0}\left(\underline{r}^{3}\right) u_{3}\left(\underline{r}^{3}\right) d r^{3}\right]^{k_{3}} \ldots
\end{aligned}
$$

Using this approximation equation (7) can be written as

$$
\Xi(\mu, V, T)=\Xi_{0}(\mu, V, T)\left[1+\sum_{k=2}^{\infty} \sum_{k_{2} k_{3} \ldots} \frac{\left(\beta V P_{2}\right)^{k_{2}}}{k_{2} !} \frac{\left(\beta V P_{3}\right)^{k_{3}}}{k_{3} !} \ldots\right]
$$

where

$$
\beta P_{e}=\frac{1}{V l !} \int n_{e}^{0}\left(\underline{r}^{e}\right) U_{e}\left(\underline{r}^{e}\right) d \underline{r}^{e}
$$

and $\quad \sum_{e} l k_{e}=k$

Due to the property of the cluster functions mentioned earlier, the integrals in $\mathrm{P}_{\ell}-\mathrm{s}$ are proportional to $\mathrm{V}$, since once the coordinates of one of the particles have been fixed, the region of integration (where the integrand differs from zero) is reduced to a finite volume determined by the range of interaction of the potential. Thus $\mathrm{P}_{\ell}-\mathrm{s}$ remain finite in the thermodynamic limit 
when $\mathrm{V}$ tends to infinity. After some manipulation we get

$$
\begin{aligned}
\Xi(\mu, v, T)= & \Xi_{0}(\mu, v, T) \prod_{e=2}^{\infty} \sum_{k_{e}=0}^{\infty} \frac{\left(\beta V P_{e}\right)^{k_{l}}}{k_{l} !}= \\
& \Xi_{0}(\mu, V, T) e^{\beta V \sum_{e=2}^{\infty} P_{e}}
\end{aligned}
$$

and the equation of state:

$$
P=P_{0}+\sum_{e=2}^{\infty} P_{e}
$$

If the reference system is an ideal gas $\left(i \cdot e \cdot n_{k}\left(\underline{r}^{k}\right)=\rho_{0}^{k}\right.$ ), the equation (1la) is just the well known activity expansion of the equation of state. In this case $\beta P_{0}=\rho_{0}=e^{\beta \mu} / \lambda^{3}$ and $\beta P_{e}=\rho_{0}^{\ell} b_{l}$ where $b_{e}-s$ are the usual reducible group integrals which depend on the temperature but not on the volume. The density of the system is given by the equation

$$
\begin{aligned}
\rho & =\left(\frac{\partial P}{\partial \mu}\right)_{V_{1} B}=\rho_{0}+\left(\frac{\partial \rho_{0}}{\partial \mu}\right)_{V_{1} B} \sum_{l=2}^{\infty} \frac{\partial P_{l}}{\partial \rho_{0}} \\
& =\rho_{0}\left[1+\left(\frac{\partial P_{0}}{\partial \rho_{0}}\right)^{-1} \sum_{l=2}^{\infty} \frac{\partial P_{l}}{\partial \rho_{0}}\right]
\end{aligned}
$$

The equations (lla-b) are the basic equations of the method. These equations allow us to express the pressure in terms of the density (and not with the density of the reference system) which is more convenient and more usual for comparing the 
theoretical and experimental equation of state. The solution of this problem is equivalent to the invertation of the function $\rho\left(\rho_{0}\right)$ given by the equation (1lb). In the usual cluster expansion during this procedure only the irreducible cluster integrals remain as the coefficients of the power series in $\rho$. Here, however, the situation is different, since in our case the "group integrals" $P_{\ell}$ are not "reducible", because in the integrals the cluster functions are weighted by different distribution functions for the reference system. Thus the invertation is more complicated here than in the usual cluster expansion and it can not be carried out in general for every potential at arbitrary density. On the other hand from the equation (11b) one can see that the problem of invertation has automatically been solved if we could choose the reference system in such a way that $\sum P_{e}^{\prime}$ should disappear at arbitrary density (in general, this implies the use of different reference systems for different densities). We will discuss this condition $\left(\rho=\rho_{0}\right)$ later in connection with the optimal choice of the reference system. Keeping in mind the important role of the case $\rho=\rho_{0}$ for the solution of the problem and that the verification of the next procedure should be carried out in each case separately, we proceed in the following way.

First, we will rewrite the equations (lla-b) in a different form. Using the definition (2) of the cluster functions, it is easy to show that 


$$
\begin{aligned}
u_{2}\left(r_{1} r_{2}\right) & =e^{-\beta \nu\left(r_{12}\right)}-1=f_{12}=\xi e_{0}^{-1}\left(r_{12}\right) \Delta e\left(r_{12}\right) \\
u_{3}\left(\underline{r}_{1} r_{2} r_{3}\right) & =f_{12} f_{23} f_{31}+f_{12} f_{23}+f_{12} f_{31}+f_{23} f_{31} \\
& \vdots
\end{aligned}
$$

where the Mayer-function $f(r)$ is constructed now from the potential difference $v(r)=u(r)-u_{0}(r)$. Here we introduced the formal parameter $\boldsymbol{\xi}$, the power of which is equal to the order of the corresponding term in $\Delta e$ i.e. to the number of the Boltzmann-factor differences appearing in this term ( $\boldsymbol{\xi}$ plays the role of a kind of softness parameter ${ }^{7}$ ). In the expression for $U_{i}$ the lowest order term in $\xi$ (or in $\Delta e$ ) contains i-l f-functions (to connect $i$ points with each other one needs at least i-1 "bonds") i.e. its order is $\xi^{i-1}$. Substituting (12) into (10) and (11) and collecting the terms of the same order in $\xi$, we get a functional series expansion in the difference of the Boltzmann factors $\Delta e(r)$ (which is just the funcional Taylor series of the pressure):

$$
P=P_{0}+\sum_{i=1}^{\infty} \xi^{i} \Pi_{i}\left(\rho_{0}\right)
$$

and

$$
\frac{\rho}{\rho_{0}}=1+\left(\frac{\partial P_{0}}{\partial \rho_{0}}\right)^{-1} \sum_{i=1}^{\infty} \xi^{i} \frac{\partial \Pi_{i}}{\partial \rho_{0}}
$$

From (10) and (12) one can see that 


$$
\begin{aligned}
\beta \xi \Pi_{1} & =\frac{1}{2} \int n_{2}^{0}(\underline{r}) f(\underline{r}) d \underline{r} \\
\beta \xi^{2} \Pi_{2} & =\frac{1}{2} \int n_{3}^{0}\left(r, r^{\prime}\right) f(\underline{r}) f\left(r^{\prime}\right) d \underline{r} d \underline{r}^{\prime} \\
& :
\end{aligned}
$$

For convenience we introduce now the following function:

$$
\begin{aligned}
\nu\left(\rho_{0}\right)=\ln \frac{\rho_{0}}{\rho} & =\ln \left[1+\left(\frac{\partial P_{0}}{\partial \rho_{0}}\right)^{-1} \sum_{i=1}^{\infty} \xi^{i} \frac{\partial \Pi_{i}}{\partial \rho_{0}}\right]^{-1} \\
& =\sum_{i=1}^{\infty} \xi^{i} \nu_{i}\left(\rho_{0}\right)
\end{aligned}
$$

At the same time this equation defines the functions $\nu_{i}\left(\rho_{0}\right)$. From the definition (15) we can see that the solution of invertation is equivalent to the determination of the function

$$
\tilde{\nu}(\rho)=\nu\left(\rho_{0}(\rho)\right)
$$

for which we take the form

$$
\tilde{\nu}(\rho)=\sum_{i=1}^{\infty} \xi^{i} \tilde{\nu}_{i}(\rho)
$$

Now we expand $\nu\left(\rho_{0}\right)$ into a power series in $\ln \rho_{0}-\ln \rho$

$$
\nu\left(\rho_{0}\right)=\nu(\rho)+\sum_{i=1}^{\infty} \frac{\nu^{(i)}(\rho)}{i !}\left[\nu\left(\rho_{0}\right)\right]^{i}
$$

where the superscript (i) denotes the i-th derivative with respect to $\ln \boldsymbol{\rho}$. Substituting the power series expansion of $\nu$ 
and $\tilde{\nu}$ in $\xi$ into the equation (17) and using the equality (16), we can determine the functions $\tilde{\nu}_{i}(\rho)$ in terms of the functions $\nu_{i}(\rho)$ and their derivatives, if we compare the terms of the same order in $\xi$ of the two sides of equation (17). Thus we get

$$
\begin{aligned}
& \tilde{\nu}_{1}(\rho)=-\frac{\Pi_{1}^{\prime}(\rho)}{P_{0}^{2}(\rho)} \\
& \tilde{\nu}_{2}(\rho)=-\frac{\Pi_{2}^{\prime}(\rho)}{P_{0}^{\prime}(\rho)}+\frac{1}{2}\left[\rho\left(\frac{\Pi_{1}^{\prime}(\rho)}{P_{0}^{\prime}(\rho)}\right)^{2}\right]^{\prime}
\end{aligned}
$$

where the prime denotes the derivative with respect to $\rho$. After the determination of the function $\widetilde{\nu}(\rho)$ we can easily express the thermodynamic quantities as a function of $\rho$. It directly follows from the grand canonical description that the chemical potential of the system at $\rho$ is equal to that of the reference system at $S_{0}$, that is the excess chemical potential $\mu_{\text {ex }}(\rho)$ is given by the equation

$$
\beta \mu_{e x}(\rho)=\beta \mu_{e x}^{0}\left(\rho_{0}\right)+\tilde{\nu}(\rho)
$$

Expanding $\mu_{\text {ex }}^{0}$ into a power series in $\ln \rho_{0}-\ln \rho$ and taking the function $\tilde{\nu}(\rho)$ from $(18)$, we obtain an expression for $\mu_{\text {ex }}^{0}\left(\rho_{0}\right)$ as a function of $\boldsymbol{\rho}$ in the form of a power series in $\bar{\xi}$. Substituting this expression to the equation (19), we obtain the excess chemical potential of the system as a function of $\rho$ :

$$
\mu_{\text {ex }}(\rho)=\mu_{e x}^{0}(\rho)-\xi \Pi_{1}^{\prime}-\xi^{2}\left[\Pi_{2}^{\prime}-\frac{1}{2}\left(\rho \frac{\Pi_{1}^{\prime 2}}{p_{0}^{\prime}}\right)^{\prime}\right] \ldots
$$


The excess free energy per particle $a(\rho)=\frac{\beta A_{\text {ex }}}{N}$ can be obtained directly from (20) using the relation

$$
\beta \mu_{e x}=\frac{\partial(\rho a)}{\partial \rho}
$$

Thus we have

$$
a(\rho)=a_{0}(\rho)-\xi \frac{\beta \Pi_{1}}{\rho}-\xi^{2}\left[\frac{\beta \Pi_{2}}{\rho}-\frac{1}{2} \frac{\left(\beta \Pi_{1}^{\prime}\right)^{2}}{\beta P_{0}^{\prime}}\right] \ldots
$$

The expression for the pressure can be obtained by differentiating the equation (21).

After calculating the thermodynamic quantities we turn now to the determination of the pair distribution function for the system. In principle we could start from the definition of the pair correlation function and carry out a calculation similar to the derivation of the thermodynamic quantities, analogously to that of the usual cluster expansion of the pair correlation function. We can proceed, however, in a more simple way if we start from the expression (21) and use the relation ${ }^{7}$ which expresses the pair correlation function as the functional derivative of the excess free energy with respect to the potential u(r):

$$
n_{2}\left(r_{12}\right)=2 \rho \frac{\delta a}{\delta \beta u\left(r_{12}\right)}
$$

From equations (21) and (22) we can obtain an expression for the pair correlation function in the form of a series expansion 
in $\xi$. We have introduced here the function $y_{2}$ by the usual definition $n_{2}(r)=e(r) \rho^{2} y_{2}(r)$. Thus

$$
\begin{gathered}
\left.y_{2}(r)=y_{2}^{0}(r)+2 \rho 5\right] y_{3}^{0}\left(r, r^{\prime}\right) \Delta e\left(r^{\prime}\right) d r^{\prime} \\
-\xi \frac{\Pi_{1}^{\prime}}{\rho P_{0}^{\prime}}\left[\rho^{2} y_{2}^{0}(r)\right]^{\prime}+\ldots
\end{gathered}
$$

where $y_{3}^{0}$ is defined by the relation

$$
n_{3}^{0}\left(r, r^{\prime}\right)=e_{0}\left(r \mid e_{0}\left(\underline{r}^{\prime}\right) g^{3} y_{3}^{0}\left(\underline{r}_{1} \underline{r}^{\prime}\right)\right.
$$

The zeroth order term in the softness parameter $\xi$ gives back the well known result ${ }^{7}$ that

$$
y_{2}(r)=y_{2}^{0}(r)
$$

\section{Discussion}

In this section we comment on the errors introduced by the decoupling assumption (9) and investigate the differences between the applications of the equations (1la-b) and (21). Finally we will discuss the problem of the optimal choice of the reference system. We mentioned in the introduction that if we do not use the approximation (9), we obtain corrections to the equations $(11 \mathrm{a}-\mathrm{b})$. The determination of these correction terms is easier by using the diagrammatic expansion technique and it will be published elsewhere ${ }^{8}$. To illustrate the effect of these corrections we show the form of the lowest order correction which is of the type 


$$
\int\left[n_{4}^{0}\left(\underline{r}^{4}\right)-n_{2}^{0}\left(r_{12}\right) n_{2}^{0}\left(r_{34}\right)\right] f\left(r_{12}\right) f\left(r_{34}\right) d r_{2} d r_{3} d r_{4}
$$

i.e. it means a contribution to the expansion of the order of $\xi^{2}$. With a suitable choice of the reference system (which is necessary to obtain a successful description in any case) these corrections become usually negligible. Besides, in applications these corrections are of little importance, since the higher order correlation functions of the reference system are, in most of the cases, unknown.

Let us now turn to the discussion of the differences between the results derived from equations (1la-b) and those obtained from equation (21). Comparing the two equations one can see that if we start from the equations (1la-b) keeping only the zeroth and first order terms in $\boldsymbol{\xi}$, and solve the problem of invertation exactly (e.g. we determine the reference system from the condition $\left.\rho=\rho_{0}\right)$, the result will contain the sum of an infinite subseries compared to the calculation which starts from the equation (21) and takes into account only the zeroth and first order terms (the accuracy of the two descriptions is equivalent only in the case $\rho=\rho_{0}$ when the sum of this subseries equals to zero). This can be seen from the equation (21), where the derivative of $\Pi_{1}$ appears in the second order term (and its higher derivatives appear in the higher order terms). Therefore we expect to obtain more accurate results starting from the equations $(11 \mathrm{a}-\mathrm{b})$ if we know, say, only the pair correlation 
function of the reference system, because in this case the result of first order in $\xi$ will contain all the terms of (21) which can be expressed by the pair function or its derivatives with respect to $\rho$.

At this point we have reached the problem of the optimal choice of the reference system. This problem arises from the fact that we do not have complete information about the distributional properties of the reference system; in most of the cases we know only its pair correlation function. The optimal choice of the reference system means the minimization of the higher order terms concerning one or more thermodynamic quantities. One of the most successful optimization procedures was proposed by Andersen et al. ${ }^{7}$, in which the reference system is determined from the condition that the first order term in (21) should vanish at arbitrary density and at the same time the magnitude of the higher order terms is reduced. In this method the compressibility is the thermodynamic quantity which is taken to be equal for the two systems. Returning now to the condition $\rho=\rho_{0}$ which takes some parts of the higher order terms of the expansion exactly equal to zero, we can see from the equation (19) that in this case the chemical potentials of the two systems of the same density are equal to each other. Thus the condition $\rho=\rho$ physically means that we choose the reference system in such a way as if it were in chemical equilibrium with the system under consideration. Taking into account only the first order term in 5 , the condition $\rho=\rho_{0}$ will appear in a form similar to that proposed by Andersen et al., but now in the integral the 
difference of the Boltzmann factors is weighted by the derivative of the pair distribution function of the reference system with respect to the density, and not by the pair correlation function itself:

$$
\int\left[\rho^{2} y_{2}^{0}(r)\right]^{\prime} \Delta e(r) d \underline{r}=0
$$

This condition will be tested in the following paper for systems with inverse power potentials using a hard sphere reference system and the results will be compared to those obtained by using the method of Andersen et al.

Finally we discuss the problems appearing in the determination of the pair correlation function. In zeroth order approximation the determination of the pair function is completely analogous to that proposed by Andersen et al. The only differience appears in the way of choosing the reference system, for which - for the reasons mentioned above - we propose the condition (25) when $S=S_{0}$. In this order the pair function satisfies the compressibility equation and tends to unity for large distances. A new problem arises, however, if we determine the pair function in the next order from the equation (23). Namely the lowest order correction arising from the use of the approximation (9) appears in this order (which comes from the correction to the second order term of the free energy shown in (24)) and the pair correlation function does not satisfy the compressibility equation and does not go to unity for large distances any more for an arbitrary reference system. However, one can 
avoid these difficulties by choosing the reference system in such a way that the decoupling of the cluster integrals should mean a consistent description in this order as well. This can be reached in the following way. The derivative of the pair distribution function with respect to the density can be expressed as $^{10}$

$$
n_{2}^{0}(r)=\frac{\beta P_{0}^{\prime}}{\rho}\left[2 n_{2}^{0}(\underline{r})+\int\left(n_{3}^{0}\left(r \underline{r}^{\prime}\right)-\rho n_{2}^{0}(r)\right)\right]
$$

Thus in the calculation of an integral of the type

$$
\int n_{2}^{0}(r) f(r) d \underline{r}
$$

the consistent application of the decoupling assumption (9) would mean that the integral coming from the second term of the right hand side of equation (26) should vanish, that is we obtain the equation

$$
\Pi_{1}^{\prime}=\frac{2 \beta P_{0}^{\prime}}{\rho} \Pi_{1}
$$

The equation (27) can serve as a condition for choosing the reference system in the first order calculation of the pair correlation function (and in the second order calculation for the free energy. In this case we can use for instance the Kirkwood superposition approximation ${ }^{11}$ for the three-particle 
correlation function). It is easy to show that if the equation (27) is satisfied, the pair correlation function obtained in this way satisfies the compressibility equation and it goes to unity for large distances. In the following paper we will give numerical examples for both the zeroth and the first order determination of the pair correlation function from the condition $\rho=\rho_{0}$ and from the equation (27), respectively, for a system with inverse twelfth power potential using a hard sphere reference system.

\section{Conclusion}

To summarize, we developed a perturbational method in which the thermodynamic properties and the pair correlation function of a real fluid are expressed with the thermodynamic quantities and the distribution functions of a reference system in the form of a power series in a softness parameter. In this form the method (being a kind of a $\boldsymbol{\xi}$-expansion) is appropriate for treating rapidly varying perturbations in a narrow range of $r$, but expanding the difference of the Boltzmann factors with respect to the potential difference, we can recover the formulas of the high temperature expansion as well. The method in its present form contains an approximation which enables us to obtain the results in a simple, physically transparent form allowing us to take into account some parts of the higher order 
terms of the usual $\rho$-dependent form for the thermodynamic quantities using lower order terms (those parts, that can be expressed in terms of the derivatives of lower order distribution functions). In this sense the present method makes full use of the information content of low order correlation functions and therefore we expect to achieve higher accuracy compared to the usual methods, for example in the special case when we know only the pair correlation function of the reference system. Moreover we proposed new conditions for the optimal choice of the reference system for both the first and the second order determination of the free energy of the system.

\section{Acknowledgments}

The author is indebted to Drs. P. Fazekas, F. Iglói and A. Sütô for many valuable discussions. 


\section{REFERENCES}

1. R. Zwanzig, J. Chem. Phys. 22, 1420 (1954)

2. P. C. Hemmer, J. Math. Phys. 5, 75 (1964), and

J. L. Lebowitz, G. Stell, S. Baer, J. Math. Phys. 6, 1282 (1965)

3. H. C. Andersen, D. Chandler, J. Chem. Phys. 57, 1918 (1972)

4. For a comprehensive review see e.g. J. Barker, D. Henderson, Rev. Mod. Phys. 48, 587 (1976), or

J. P. Hansen, I.R. McDonald, Theory of Simple Liquids, Academic Press, London-New York-San Francisco, 1976.

5. J. S. Rowlinson, Mol. Phys. 8, 107 (1964)

6. J. A. Barker, D. Henderson, J. Chem. Phys. 47, 4714 (1967)

7. H. C. Andersen, J. D. Weeks, D. Chandler, Phys. Rev. A $\underline{4}$, 1597 (1971)

8. F. Iglói, J. Kollár (to be published)

9. D. ter Haar, Elements of Statistical Mechanics, Chapter 8 . Holt, Rinehart and Winston, New York, 1960

10. P. Schofield, Proc. Phys. Soc. 88, 149 (1966)

11. See, e.g. S. A. Rice, P. Gray, Statistical Mechanics for Simple Liquids, Interscience, New York, 1965, Sec. 2.6. 


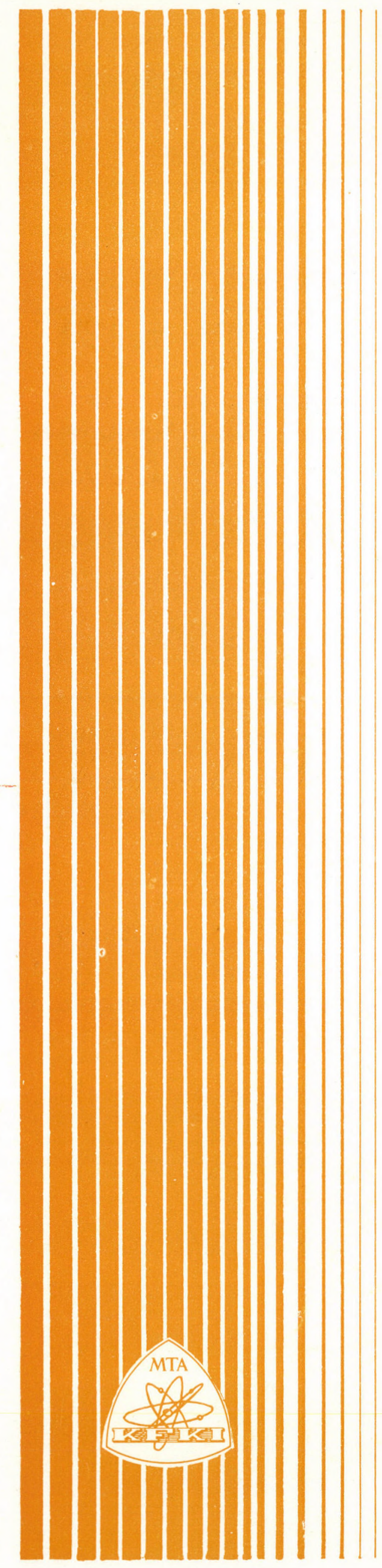

Kiadja a Központi Fizikai Kutató Intézet Felelõs kiadó: Krén Emil

Szakmai lektor: Fazekas Patrik Nyelvi lektor: Bergou János példányszám: 495 Törzsszám: 80-653 Készült a KFKI sokszorositó üzemében Felelós vezetō: Nagy Károly

Budapest, 1980. október hó 